\title{
Community activism as a strategy to reduce intimate partner violence (IPV) in rural Rwanda: Results of a community randomised trial
}

Sangeeta Chatterji ${ }^{1}$,

Erin Stern ${ }^{2,5}$, Kristin

Dunkle $^{2}$, Lori Heise ${ }^{1,4,5}$

${ }^{1}$ Johns Hopkins Bloomberg School of Public Health, Johns Hopkins University, Baltimore, Maryland, USA

${ }^{2}$ Gender and Health Research Unit, South African Medical Research Council, Cape Town, South Af

${ }^{4}$ Johns Hopkins School of Nursing, Johns Hopkins University, Baltimore, Maryland, USA

${ }^{5}$ London School of Hygiene and Tropical Medicine, London, UK

(affiliation at start of project)

\section{Correspondence to:}

Dr. Lori Heise, Professor

Johns Hopkins Bloomberg School of Public Health

615 N. Wolfe Street

Room E4644

Baltimore, Maryland 21205

USA

lheise1@jhu.edu
Background There is considerable interest in community organising and activism as a strategy to shift patriarchal gender norms, attitudes and beliefs and thus reduce intimate partner violence (IPV). Yet there is limited insight into how activism actually translates into reduced violence, including how aspects of programme implementation or cultural context may affect impact. This study evaluates the community activism/mobilisation portion of Indashyikirwa, a multi-component, IPV prevention programme implemented in rural Rwanda. The activism part of Indashyikirwa was based on SASA!, a promising program model from Uganda with demonstrated effectiveness.

Methods We implemented two separate cross-sectional surveys as part of a larger community randomised controlled trial to assess the impact of the community portion of Indashyikirwa on preventing physical and/or sexual IPV and other secondary outcomes at a community level. The survey consisted of a random household-based sample of 1400 women and 1400 men at both waves. Surveys were conducted before community-level activities commenced and were repeated 24 months later with a new cross-sectional sample. Longitudinal, qualitative data were collected as part of an embedded process evaluation.

Results There was no evidence of an intervention effect at a community level on any of the trial's primary or secondary outcomes, most notably women's experience of physical and/or sexual IPV from a current male partner in the past 12 months (adjusted odds ratio $(\mathrm{aOR})=1.25 ; 95 \%$ confidence interval $(\mathrm{CI})=0.92$ $1.70, P=0.16)$, or men's perpetration of male-to-female physical and/or sexual IPV $(\mathrm{aOR}=1.02 ; 95 \% \mathrm{CI}=0.72-1.45, P=0.89)$. Process evaluation data suggest that delays due to challenges in adapting and implementing SASA!-style activites in rural Rwanda may account for the trial's failure to measure an effect. Additionally, the intervention strategy of informal activism was not well suited to the Rwandan context and required considerable modification.

Conclusions Failure to reduce violence when implementing an adaptation of SASA! in rural Rwanda highlights the importance of allowing sufficient time for adapting evidence-based programming (EBP) to ensure cultural appropriateness and fidelity. This evaluation held little chance of demonstrating impact since the project timeline forced endline evaluation only months after certain elements of the programme became operational. Donors must anticipate longer time horizons (5 to 7 years) when contemplating evaluations of novel or newly-adapted programmess for reducing IPV at a population level. These findings also reinforce the value of including embedded process evaluations when investing in rigorous trials of complex phenomena such as community activism.

Trial registration ClinicalTrials.gov, NCT03477877 
Intimate partner violence (IPV) is a critical global health issue that affects 30\% of women worldwide [1]. Emerging evidence affirms that levels of IPV can be reduced and suggests several promising areas for intervention. Community activism to shift the patriarchal norms, attitudes and beliefs that undergird IPV is one strategy that has garnered considerable attention in recent years. Rigorous trials in sub-Saharan Africa have demonstrated that community activism, mobilisation, and organised diffusion can be effective in reducing IPV [2-5]. For example, SASA! and SHARE, both community mobilisation programs implemented in Uganda, documented reductions in women's experiences of IPV over 4 years as well as shifts in the attitudes, beliefs, and social norms perceived to perpetuate such violence $[3,6,7]$. Importantly, other mobilisation and community activism interventions have found no such impact on IPV [8,9], suggesting that implementation and context are crucial for achieving gains in safety and well-being at the community level.

Moreover, there is limited understanding of how activism actually translates into reduced violence, including how cultural context and programme implementation may affect impact. Process evaluations have uncovered unforeseen challenges such as lack of institutional support for staff and activist volunteers [8] and individual factors such as illness, family, and economic pressures that have negatively impacted the success of some mobilisation interventions [10]. Trials of community-based IPV interventions remain scarce given the high costs and methodological challenges of evaluating complex interventions designed to catalyse widespread social change and shift harmful social norms [11,12].

In this paper, we report on an impact evaluation of a large-scale community activism/mobilisation programme implemented as part of a multi-component intervention to reduce IPV in rural Rwanda. The programme, known as Indashyikirwa ("Agents of Change" in Kinyarwanda, trial identifier: NCT03477877), was implemented by CARE International, Rwanda; the Rwanda Women's Network (RWN); and the Rwanda Men's Resource Centre (RWAMREC) between 2015 and 2018, with funding from the Rwandan office of the Department for International Development (DFID-R). The full Indashyikirwa program included four interlocking components: a 21-session couples' curriculum; community outreach by trained community activists; the creation of an enabling environment through training and active involvement of key opinion leaders; and provision of support to victims through the creation of women's "safe spaces" [13,14].

This paper reports exclusively on the evaluation of the community activism portion of the intervention, conducted by external researchers funded by DFID UK as part of a separate initiative known as What Works to Prevent Violence Against Women and Girls. The findings reported herein derive from two repeat cross-sectional surveys of community members, conducted as part of a larger community randomised trial, with qualitative data from a nested process evaluation [15]. A separate manuscript reports on the impact that the couple's curriculum had on relationship dynamics and IPV levels among couples who participated in the programme's 5-month couples' curriculum (for more details on the couple's curriculum, see [13]). Longitudinal evaluation of the couples' programme demonstrated that couples who participated in the training reported less physical, sexual, emotional, and economic IPV; improved relationship quality; better communication; improved conflict management; fewer depressive symptoms; better oveall health; and attitudes less supportive of wife beating, than did control couples at 12 and 24 months followup [16]. This paper reports on the community-wide elements of Indashyikirwa including activist activities, implementation of women's safe spaces and training of local opinion leaders. We assess the extent to which these activities impacted community-level experience and perpetration of physical and/or sexual violence, attitudes towards violence, support for survivors and how the results relate to the design and implementation of the intervention.

\section{Background and intervention design}

Indashyikirwa was implemented in seven districts in the Eastern, Northern and Western provinces of Rwan$\mathrm{da}$, in predominantly rural, widely-dispersed communities. Although the Rwandan government enacted the Prevention and Punishment of Gender-Based Violence Law in 2008, IPV is a persistent phenomenon in Rwanda, as in many other settings. According to the 2014-15 Rwanda Demographic and Health Survey, 34\% of women aged 15 to 49 in the general population experienced physical and/or sexual violence by a husband/partner in the past 12 months [17].

It was against this backdrop that CARE Rwanda, together with RWAMREC and RWN, sought to design and implement an evidence-informed programme to reduce violence within intimate partnerships in Rwanda. The original idea was to build from the experiences of the partner organisations and from insights generated from an earlier evaluation of SASA!, a programme designed by the Ugandan NGO, Raising Voices, to reduce HIV and IPV $[7,18]$. Raising Voices, together with the local CBO, CEDOVIP, successfully reduced 
the population prevalence of current sexual and/or physical IPV by 52\% (a 16 pp absolute decrease in physical IPV) in a high density area of Kampala over 4 years [7].

Table 1 briefly summarises the original SASA! programme, and notes how Indashyikirwa compares with SASA! [13]. In the results and discussion sections of this paper, we further explore ways that Indashyikir$w a$, as implementated, departed from the SASA! model and from Indashyikirwa's original design.

Most notably, Indashyikirwa added an intensive 21-session couple's curriculum intended to promote healthy relationships, increase couple communication, and decrease male control and violence. This decision was both tactical and strategic. It built on earlier evidence that SASA!'s impact on IPV was partially mediated through improved couple relationships, a mechanism of impact not originally emphasised in the SASA! theory of change [5]. Additionally, Raising Voices and Center for Domestic Violence Prevention (CEDOVIP) trained community activists slowly over time (inviting them to mini-trainings to learn new content incrementally over two years, then sending them back into the community to share this new

Table 1. Comparison of Indashykirwa and SASA!

\begin{tabular}{ll} 
Programine & SASA! model By RaISIng VoICES \\
$\begin{array}{l}\text { Location of } \\
\text { Intervention }\end{array}$ & Kampala, Uganda (urban informal settlement) \\
\hline $\begin{array}{l}\text { Components } \\
\text { of Interven- } \\
\text { tion }\end{array}$ & $\begin{array}{l}\text { Four strategies (communication materials, media and advocacy, } \\
\text { local activism and training) implemented over four phases. Each } \\
\text { phase focuses on a different outcome: Start (knowledge), Aware- } \\
\text { ness (attitude), Support (skills), Action (behavior). }\end{array}$
\end{tabular}

INDASHYIKIIIWA AS IMPLEMENTED IN RWANDA

14 districts across rural Rwanda; trainings and coordination meetings took place centrally with activists doing outreach in disparate villages

session couples' curriculum focuses on gender, power, relationship skills, triggers of violence, harmful alcohol use, sexuality, etc.; 16 additional sessions on activism skills with a sub-set of couples trained as community activists (CAs); Activities undertaken at village level by trained CAs; Creation and staffing of women's safe spaces; Engagement of opinion leaders through training and ongoing coordination meetings

Approach Community activists (CAs) encourage reflection and promote Activists primarily conducted activities at more formal venues, inaction on power and violence through informal engagement with cluding at village savings and loans meetings, community meetcommunity members, relying on "quick chats," games, drama, and ings, umuganda days, domestic violence committees, and parents creative communication materials and techniques, rather than on evening forums, although this shifted to more informal settings by workshops, or speaking at formal public events (SASA Fidelity Brief) the end of the programme

Phasing The Start Phase nurtures one's 'power within,' the Awareness Trainings with couples, community activists, opinion leaders and Phase deepens analysis of men's 'power over' women and the women's safe space facilitators included elements from all phases; communities silence about this, the Support Phase fosters join- For the community activism component, the Start and Action ing 'power with' others, and Action Phase encourages the use of phases, and Support and Awareness phases were merged giv'power to' make and sustain positive change

en that adaptation-related needs and processes took longer than originally expected

Duration of 3-5 years to complete all phases of activism activities

1 year for inception and design of intervention; 9 mo establishment of women's safe spaces; training of opinion leaders and couples curriculum; 3 mo selection and training of activists; 18 mo for activism led by sub-set of couples and operation of women's safe spaces (see timeline)

Preparation 8 hours of training at the beginning of each phase

21 sessions of 3 hours each for couples; 2 weeks of 16 additional of staff and sessions on activism

activists

Field Officers At least one dedicated staff member to regularly support and menper Activist tor twenty-five community activists (SASA Fidelity Brief)

One RWN staff member for every twenty-two women's safe space facilitators and one RWAMREC staff member for every forty community activists

Implemen- Monitoring and evaluation tools assess progress at each phase and Trainings with couples, community activists, opinion leaders and

tation of

Phased Pro-

determine readiness for the subsequent phase women's safe space facilitators included elements from all phases

gramming

Activism

Tools and

Strategies

\begin{abstract}
The Communication Materials strategy include creative and posi- From Communication Materials the power posters, community tive materials, such as posters, comics and info-sheets, to support posters and picture cards from various phases were adapted for community members to think and talk about power and violence use by activists and safe space facilitators. Some materials from this against women. The Local Activism strategy includes initiatives that strategy were not adapted for being less relevant to the Rwandan create informal opportunities for personal reflection, critical think- context, such as the card games and comic strips. SASA! Faith coming and public dialogue about power and violence

against women. The Media \& Advocacy strategy aims to influence public priorities, by making violence against women a popular media topic and by engaging local leaders, policymakers and journalists and includes soap operas, operas, fact sheets, PowerPoints, and leadership leaflets. The Training strategy includes modules suitable for anyone exploring their potential as activists, designed to guide participants in developing a passion for and skills in creating positive change, which are offered according to the four phases. munication materials were also adapted. From the Local Activism strategy community conversations, community dramas and quick chats (including revised healthy relationship chats to have a stronger emphasis on couples) were adapted. Materials from the Media and Advocacy strategy were not adapted for Indashyikirwa, as the programme used other innovations including the training and engagement of opinion leaders. The Training strategy informed the curricula with opinion leaders, women's space facilitators, couples, and activists. The refresher trainings were not implemented in a phased approach but rather conducted on a more ad hoc basis in response to identified needs.
\end{abstract}


knowledge). This strategy was viable in their context because both organisations were co-located in the Kampala communities where they implemented SASA!. The desire to implement Indashyikirwa at scale in multiple provinces meant that partners needed a strategy to prepare community members for activism that did not require repeatedly convening widely dispersed activists. The couple's curriculum offered a mechanism to both strengthen the relationship and skills-building element of the programme while condensing the time and costs of preparing community members to serve as mobilisers.

Figure 1 and Figure 2 depict the programme's ultimate implementation and research timeline as well as Indashyikirwa's theory of change. After completing the couple's programme, individuals who expressed interest and met additional criteria (in terms of literacy, commanding respect in the community, and ability to commit to 2-3 activities per month for 18 months) were invited to attend 15 supplemental sessions on community activism. These sessions emphasised how to use participatory techniques to challenge prevailing beliefs and engage community members around transforming gender norms, balancing power in

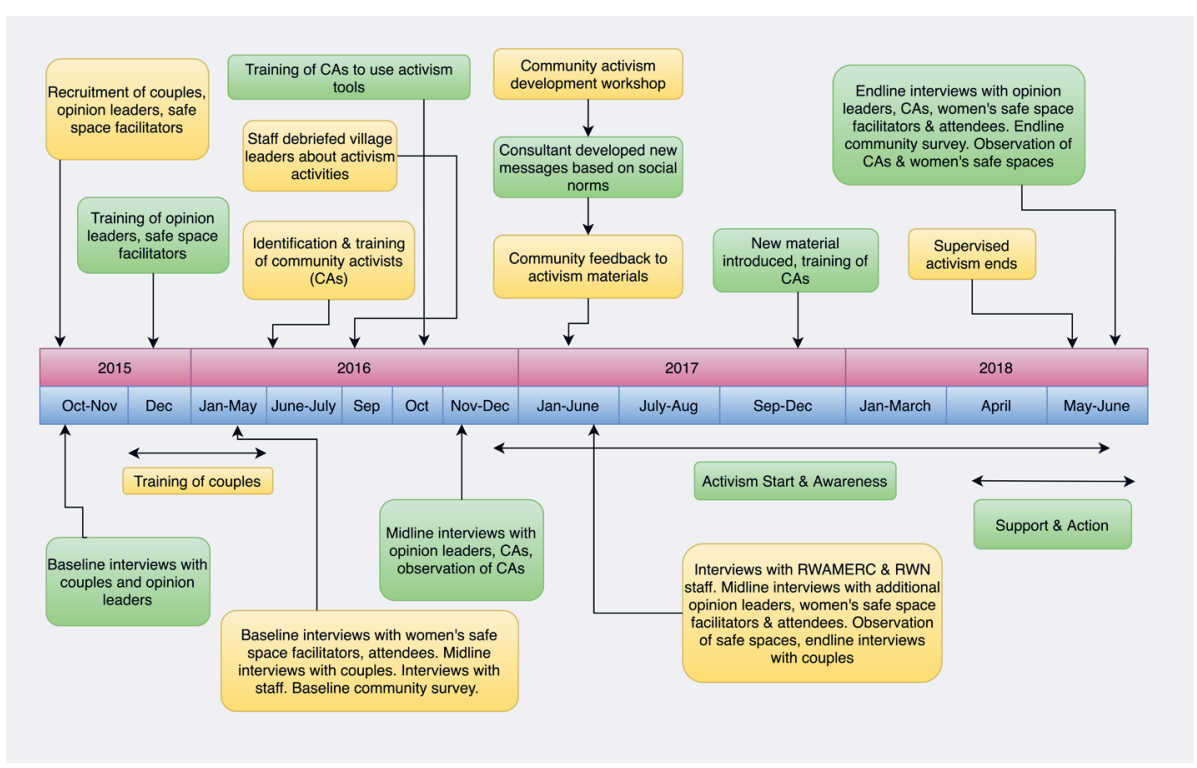

Figure 1. Timeline of intervention and research activities.

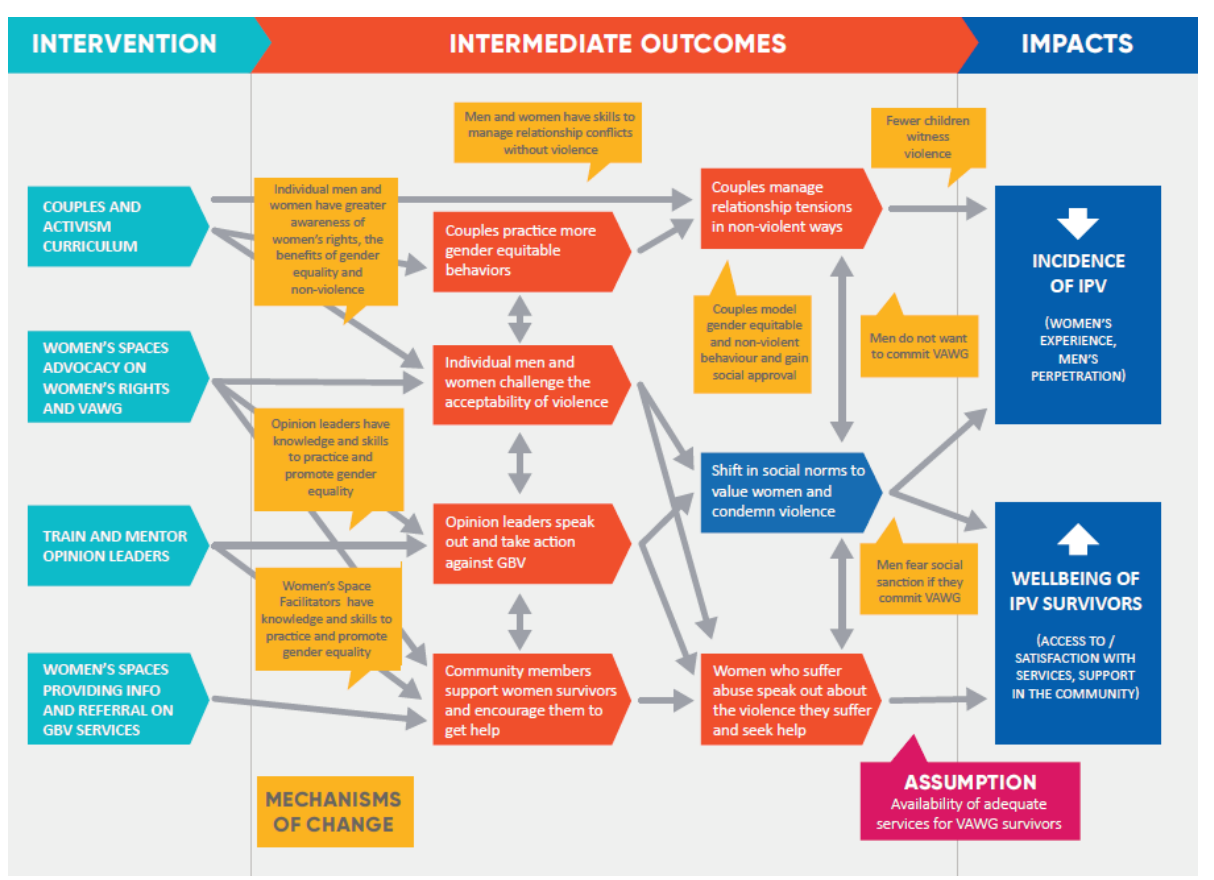

Figure 2. Indashykirwa theory of change. 
relationships and interrupting violence. RWAMREC staff both conducted this training and offered ongoing support to CAs through on-site monthly meetings.

To cultivate a supportive environment for community change, RWN likewise trained approximately forty opinion leaders per intervention sector (midlevel administrative units with an average population of 25000 people) at the beginning of the programme (eg, local government, service providers, religious leaders), and again after local elections replaced some of the incumbants in these positions. To provide additional support for victims, RWN established fourteen "safe space" drop-in centers (one per intervention sector), building on their experience since 1997 running the Polyclinics of Hope for victims of the genocide [14]. The Indashyikirwa safe spaces were staffed by trained community volunteers, recruited from the villages where the community activists were active. These volunteers facilitated sessions on IPV and women's legal rights, and accompanied women who wanted to seek assistance from health, justice and/or social services.

\section{METHODS}

The impact evaluation took the form of a community randomised controlled trial (cRCT), with randomisation at sector level, and two separate evaluation components: (1) a longitudinal cohort of couples who attended the couples intervention and couples recruited in a like manner from comparison communities, interviewed at baseline, 12, and 24 months; and (2) a pair of cross-sectional community surveys implemented near the beginning of the intervention and 24 months later. Results from the community surveys are presented in this paper.

\section{Design}

The community surveys consisted of a household-based random sample of currently partnered women and men residing in villages from the intervention and control sectors (50 men and 50 women surveyed in each of the 28 study sectors). The community survey was repeated 24 months later to assess possible community-level impact of the programme. The Indashyikirwa intervention was built on the existing infrastructure of CARE Rwanda's community-based village savings and loan associations (VSLAs). Prior to the involvement of the What Works evaluation team, the program partners chose 7 districts for implementation of Indashyikirwa, spread across Eastern, Northern and Western provinces. These districts were chosen based on examination of the Demographic and Health Survey (DHS) 2010 data to identify areas with high rates of IPV, in combination with a strong presence of CARE's VSLA program. Office-based rosters of VSLAs were used to identify sectors and cells within these districts with a likely viable concentration of VSLAs from which to recruit couples; these were then verified by an on-the-ground survey.

\section{Sampling}

An independent statistician randomised the sectors deemed viable for programme implementation into intervention and control sectors, with stratification by district. The final number of sectors per district ranged from 2 to 6 . Given that there were a fixed number of total sectors available for the study, we estimated the number of interviews per sector required to show a $25 \%$ reduction in key outcomes at $\alpha=0.05$ and $\beta=0.80$ for outcome indicators with baseline prevalences ranging from $20 \%-50 \%$. We used intra-cluster correlation coefficients (ICC) estimated conservatively at 0.15 as well as ICC $=0.10$ using a formula recommended by Hayes \& Bennet for cluster randomised control trials [19]. Based on these estimates, budget, and operational logistics, we planned for 50 interviews each with women and with men per sector, for a target of $(28 * 50)=1400$ interviews, which gave us power to detect a $25 \%$ relative reduction in IPV from baseline given a baseline prevalence of IPV $=35 \%$ if ICC $=0.15$ and given a baseline prevalence of IPV $=30 \%$ if ICC $=0.10$.

Two cells per sector were selected for implementation of the couples training or recruiting the control cohort based on having a high density of CARE VSLAs. Community surveys were then implemented in these same cells to maximise the possibility of detecting a diffusion effect. It was anticipated that CAs would primarily conduct community-level activities in their own villages or neighboring villages as they were familiar with the context and had access to support systems including other couples who underwent the couples training and their own social networks. One cell per sector was randomly allocated for conducting the women 's community survey and the other for conducting the men's survey. We conducted separate interviews of men and women in order to maximise participant privacy and safety, as suggested by the WHO ethical guidelines [20]. 
To help control field costs, the community survey was implemented in two contiguous villages within each cell. Because we were most interested in assessing potential community diffusion, site identification began by assessing where participants in the couples training or VSLA control group resided. We then purposively selected 2 adjacent villages with the highest concentrations of cohort participants to create geographic clusters for the purposes of data collection. We interviewed 50 adult women or men in each selected area. The baseline survey successfully collected data from 1399 women and 1400 men living in households within identified community sampling areas, split evenly between intervention and control areas (target 1400 each; one missing woman was ill on the day of her appointment and not replaced). Endline data were collected from 1400 women and 1400 men.

To be eligible for the community survey, individuals had to be between 18 and 49 years old, living with a partner for at least 6 months, and not directly engaged with Indashyikirwa as a community activist, trained opinion leader, women's safe space facilitator, or a member of the Couple's Cohort.

\section{Data collection}

All data recruitment and data collection was conducted by Laterite Ltd, a private Rwandan research firm. Interviews were conducted in Kinyarwanda via ACASI (audio-enhanced computer self-interviewing) or face-to-face, based on participant preference. Each participant was provided a handheld digital device (in this case, an iPod touch) which presented questions and potential answer choices on a screen while a gender-matched voice read the questions and answer choices aloud to the participant. Participants could then answer by touching the screen. Participants who were not comfortable using ACASI or preferred a face to face interview could opt for this at any point. At baseline $62.1 \%$ of women and $85.9 \%$ men completed via ACASI, $34.7 \%$ of women and $13.0 \%$ of men via face-to-face, and $3.2 \%$ of women and $1.1 \%$ via mixed administration. At endline, $86.1 \%$ of women and $90.9 \%$ of men completed via ACASI, $12.1 \%$ of women and $8.0 \%$ of men via face-to-face, and $1.8 \%$ of women and $1.1 \%$ of men via mixed administration. There was no difference between study arms in the distribution of data collection methods at either time point.

\section{Ethics and consent}

Approval to undertake the study was obtained from the Rwandan National Ethics Committee (REF: No. 340/RNEC/2015) and the National Institute of Statistics Rwanda (REF:0738/2015/10/NISR). Secondary ethics approval was also obtained from the South Africa Medical Research Council (REF: EC033-10/2015). Written consent was obtained from all participants; illiterate participants could have the form read to them by study personnel or a trusted person of their choosing.

Participants were compensated RWF 2000 (approx. US \$2.20) for their travel, and a female professional counsellor, organised by the study, was available to support particpants who experienced any distress, with services offered either in person, over the phone, or via referral at a later time.

\section{Analysis}

Table 2 presents the primary and secondary outcome measures utilised in the community surveys. We utilised multilevel modeling to compare change over time in reported outcomes between the intervention and control groups from baseline to endline. We chose to use an individual-level rather than cluster-level analysis because of the added power that it provides. We included both fixed and random effects to account for the sample design. The fixed effects terms included study arm, data collection wave, and an interaction term for study arm and data collection wave. The district in which data were collected was treated as a fixed effect, and sector (the unit of randomisation) was included as a random effects term. We used generalised linear mixed effects modeling (multilevel model for change) with a Gaussian link function to compare mean scores at end-line for all continuous outcomes [21]. For the binary outcomes, we used generalised linear mixed effects model with a logit link function to compare the effect of the intervention between the two study arms. To test for differences in outcomes over time between participants in the treatment group and participants in the control group, we included an interaction term between treatment $(0=$ control, $1=$ treatment $)$ and wave $(0=$ baseline, $1=$ endline $)$ in all models. Women from the control arm were compared with women from the intervention arm, and men from the control arm with men from the intervention arm. All models included age, education, and asset ownership as covariates. Each model also included the baseline value of the dependent variable aggregated at the sector level as a control variable. There was less than $0.2 \%$ missing data on all outcomes and covariates and we used case-wise deletion for individuals who were missing on any of the variables included in our models. Sta- 
Table 2. Outcome measures for quantitative analysis

\begin{tabular}{|c|c|c|c|}
\hline Construct & WOMEN & Men & How ASSESSED \\
\hline \multicolumn{4}{|l|}{ Primary outcome measures: } \\
\hline $\begin{array}{l}\text { Physical or sexual intimate partner violence, What } \\
\text { Works definition, past } 12 \text { months }\end{array}$ & Experience & Perpetration & $\begin{array}{l}\text { Adapted WHO violence against women tools; } 5 \text { items on physical } \\
\text { IPV, } 3 \text { items on sexual IPV, covering past } 12 \text { months. Answer choic- } \\
\text { es: never, once, a few times, many times. Coded as "yes" per What } \\
\text { Works definition is any answer > once or multiple items endorsed. }\end{array}$ \\
\hline Acceptability of wife beating (0-5) & Yes & Yes & $\begin{array}{l}5 \text { items as per DHS; coded as } 1 \text { point for each "Agree" or "Strong- } \\
\text { ly Agree" }\end{array}$ \\
\hline Actions to support victims of gender-based violence & Yes & Yes & 4 items and summative score \\
\hline \multicolumn{4}{|c|}{ Secondary and exploratory outcome measures: } \\
\hline Any physical IPV & Experience & Perpetration & An affirmative response on any of the 5 physical IPV items \\
\hline Any sexual IPV & Experience & Perpetration & An affirmative response on any of the 3 sexual IPV items \\
\hline $\begin{array}{l}\text { Economic abuse with main partner, past } 12 \\
\text { months }\end{array}$ & Experience & Perpetration & $\begin{array}{l}3 \text { items, WHO violence against women tools, coded yes for any } \\
\text { "once" or higher }\end{array}$ \\
\hline Emotional aggression & Experience & N/A & $\begin{array}{l}3 \text { items, WHO violence against women tools, coded yes for any } \\
\text { "once" or higher }\end{array}$ \\
\hline Children witnessing IPV among survivors of IPV & Yes & N/A & $\begin{array}{l}\text { Single item on frequency of children witnessing violence against } \\
\text { mother }\end{array}$ \\
\hline Help seeking among survivors of IPV & Survivors on & N/A & 2 items baseline (ever, past year); 1 item at follow-up (past year) \\
\hline
\end{tabular}

WHO - World Health Organization, IPV - intimate partner vilence, DHS - Demographic Health Survey

ta 15 (Stata Corp, College Station, TX, USA) was utilised for the data analysis and all comparisons were evaluated at a 5\% significance level.

In addition to the quantitative components, the team conducted extensive qualitative research including a detailed process evaluation to explore potential pathways of change, and assess programme exposure, implementation delivery, and fidelity [22]. The full qualitative component of the study is detailed elsewhere [23] but methods relevant to the process evaluation are summarised in Table 3. After carefully reading the transcripts, the second author established a preliminary coding structure to thematically analyse the data using NVIVO 11 software. Data was analysed sequentially and qualitative analysis was conducted prior to the quantitative analysis as it took longer for the surveys to be completed and to obtain the data from the data collection agency. The longitudinal qualitative process evaluation was used to help interpret the quantitative results.

Table 3. Summary of data sources for process evaluation

\begin{tabular}{|c|c|c|c|c|}
\hline Participants & NumBer InTERVIEWED & TIMIng & Recruttment Criteria & Scope of Enquiry \\
\hline $\begin{array}{l}\text { Women's Safe } \\
\text { Space Facili- } \\
\text { tators }\end{array}$ & 3 (1 per province) & $\begin{array}{l}\text { May } 2016 \text { (after completing pro- } \\
\text { gramme training and beginning } \\
\text { role as facilitators); June 2017; } \\
\text { June } 2018\end{array}$ & $\begin{array}{l}1 \text { facilitator per safe space re- } \\
\text { cruited by RWN staff }\end{array}$ & $\begin{array}{l}\text { Motivations to be facilitators and their impres- } \\
\text { sions of the programme training; Perceived im- } \\
\text { pact of the safe spaces and the support they re- } \\
\text { ceive as facilitators }\end{array}$ \\
\hline $\begin{array}{l}\text { Community } \\
\text { Activists }\end{array}$ & $\begin{array}{l}12=6 \text { men and } 6 \\
\text { women }(2 \text { men and } \\
2 \text { women per prov- } \\
\text { ince) }\end{array}$ & $\begin{array}{l}\text { November } 2016 \text { (after complet- } \\
\text { ing activism training and begin- } \\
\text { ning activist activities); May } 2018\end{array}$ & $\begin{array}{l}\text { Activists who had not partic- } \\
\text { ipated in couples' interviews } \\
\text { recruited by RWAMREC staff }\end{array}$ & $\begin{array}{l}\text { Impressions of the activism training, what } \\
\text { motivated them to continue as activists, what } \\
\text { they had been doing recently as activists, and } \\
\text { whether they faced any challenges }\end{array}$ \\
\hline $\begin{array}{l}\text { RWAMREC } \\
\text { and RWN } \\
\text { Staff }\end{array}$ & $\begin{array}{l}\mathbf{1 6}=9 \text { RWAMREC } \\
\text { staff and } 6 \text { RWN } \\
\text { staff and } 1 \text { CARE } \\
\text { Staff across inter- } \\
\text { vention sectors }\end{array}$ & $\begin{array}{l}\text { May } 2016 \text { (after delivering the } \\
\text { couples, opinion leaders and } \\
\text { women's space facilitators cur- } \\
\text { riculum); May 2017; Septem- } \\
\text { ber } 2018\end{array}$ & $\begin{array}{l}\text { Diversity of field officers and } \\
\text { field supervisors across vari- } \\
\text { ous intervention sectors and } \\
\text { districts }\end{array}$ & $\begin{array}{l}\text { Successes and lessons learned from facilitating } \\
\text { curricula with opinion leaders and women's safe } \\
\text { space facilitators and engaging opinion leaders } \\
\text { and operating the women's safe spaces (RWN } \\
\text { staff), and from facilitating couples' curricu- } \\
\text { lum and supporting community activism with } \\
\text { trained partners of couples (RWAMREC staff) }\end{array}$ \\
\hline
\end{tabular}

RWAMREC - Rwanda Men's Resource Centre, RWN - Rwanda Women's Network

\section{RESULTS}

Descriptive data are presented separately for women and men in Table 4 and Table 5. There were no statistically significant differences at baseline between study arms on sociodemographic measures or potential confounding variables with one exception: a higher proportion of men at baseline reported problematic alcohol use in the intervention communities (15\% vs 9\%) as compared to the control communities.

Women ranged from 15 to 49 years and were evenly distributed across arms in terms of age, with roughly $16 \%$ of women less than or equal to 25 years old, and an equal proportion (15\%), 41 years or older, at 
Table 4. Descriptive data for female participants

\begin{tabular}{|c|c|c|c|c|c|c|c|c|c|c|}
\hline \multirow[b]{3}{*}{ Variables } & \multicolumn{5}{|c|}{ BaselniNe } & \multicolumn{5}{|c|}{ Endune } \\
\hline & \multicolumn{2}{|c|}{ Intervention } & \multicolumn{2}{|c|}{ Control } & \multirow[b]{2}{*}{ P-value } & \multicolumn{2}{|c|}{ Intervention } & \multicolumn{2}{|c|}{ Control } & \multirow[b]{2}{*}{$P$-value } \\
\hline & $\mathrm{N}$ & $\%$ or mean & $\mathrm{N}$ & $\%$ or mean & & $\mathrm{N}$ & $\%$ or mean & $\mathrm{N}$ & $\%$ or mean & \\
\hline Age (years): & & & & & & & & & & \\
\hline$\leq 25$ & 115 & $16.5 \%$ & 102 & $14.6 \%$ & 0.2 & 124 & $17.7 \%$ & 109 & $15.6 \%$ & 0.3 \\
\hline $26-30$ & 181 & $25.9 \%$ & 169 & $24.1 \%$ & & 166 & $23.7 \%$ & 173 & $24.7 \%$ & \\
\hline $31-35$ & 180 & $25.8 \%$ & 167 & $23.9 \%$ & & 191 & $27.3 \%$ & 172 & $24.6 \%$ & \\
\hline $36-40$ & 121 & $17.3 \%$ & 140 & $20.0 \%$ & & 135 & $19.3 \%$ & 155 & $22.1 \%$ & \\
\hline$\geq 41$ & 102 & $14.6 \%$ & 122 & $17.4 \%$ & & 84 & $12.0 \%$ & 91 & $13.0 \%$ & \\
\hline Education: & & & & & & & & & & \\
\hline None & 102 & $15.0 \%$ & 138 & $20.1 \%$ & 0.2 & 128 & $18.0 \%$ & 129 & $18.5 \%$ & 0.7 \\
\hline Primary & 461 & $66.0 \%$ & 450 & $64.0 \%$ & & 451 & $64.4 \%$ & 429 & $61.4 \%$ & \\
\hline Secondary or above & 135 & $19.0 \%$ & 112 & $16.0 \%$ & & 121 & $17.3 \%$ & 141 & $20.2 \%$ & \\
\hline Marital status: & & & & & & & & & & \\
\hline Married & 424 & $61.0 \%$ & 404 & $58.0 \%$ & 0.6 & 391 & $55.9 \%$ & 363 & $51.9 \%$ & 0.4 \\
\hline Living as if married & 274 & $39.0 \%$ & 296 & $42.0 \%$ & & 309 & $44.1 \%$ & 337 & $48.1 \%$ & \\
\hline Polygamy: & & & & & & & & & & \\
\hline Yes & 62 & $9.0 \%$ & 80 & $11.0 \%$ & 0.3 & 81 & $12.0 \%$ & 66 & $9.4 \%$ & 0.6 \\
\hline No & 514 & $74.0 \%$ & 534 & $76.0 \%$ & & 423 & $60.4 \%$ & 468 & $66.9 \%$ & \\
\hline Do not know & 123 & $18.0 \%$ & 86 & $12.0 \%$ & & 196 & $28.0 \%$ & 166 & $23.7 \%$ & \\
\hline Children: & & & & & & & & & & \\
\hline None & 39 & $5.6 \%$ & 37 & $5.3 \%$ & 0.5 & 45 & $6.4 \%$ & 47 & $6.7 \%$ & 0.5 \\
\hline One & 100 & $14.3 \%$ & 98 & $14.0 \%$ & & 130 & $18.6 \%$ & 115 & $16.4 \%$ & \\
\hline Two & 164 & $23.5 \%$ & 157 & $22.4 \%$ & & 161 & $23.0 \%$ & 155 & $22.1 \%$ & \\
\hline Three & 163 & $23.3 \%$ & 157 & $22.4 \%$ & & 149 & $21.3 \%$ & 153 & $21.9 \%$ & \\
\hline Four or more & 233 & $33.3 \%$ & 251 & $35.9 \%$ & & 214 & $30.6 \%$ & 230 & $32.9 \%$ & \\
\hline Income: & & & & & & & & & & \\
\hline No cash & 265 & $37.9 \%$ & 242 & $34.6 \%$ & 0.1 & 359 & $51.3 \%$ & 323 & $46.0 \%$ & 0.5 \\
\hline$<$ RWF5000 & 262 & $37.5 \%$ & 248 & $35.4 \%$ & & 204 & $29.1 \%$ & 239 & $34.2 \%$ & \\
\hline RWF5001-10000 & 97 & $13.9 \%$ & 110 & $15.7 \%$ & & 77 & $11.0 \%$ & 83 & $11.9 \%$ & \\
\hline$>$ RWF10000 & 75 & $10.7 \%$ & 100 & $14.3 \%$ & & 60 & $8.6 \%$ & 54 & $7.7 \%$ & \\
\hline Debt in previous month: & & & & & & & & & & \\
\hline No debt & 134 & $19.2 \%$ & 133 & $19.0 \%$ & 0.4 & 136 & $19.4 \%$ & 133 & $19.0 \%$ & 0.3 \\
\hline$<$ RWF1000-2000 & 122 & $17.5 \%$ & 118 & $16.9 \%$ & & 190 & $27.1 \%$ & 206 & $29.4 \%$ & \\
\hline RWF2001-10000 & 191 & $27.4 \%$ & 167 & $23.9 \%$ & & 151 & $21.6 \%$ & 164 & $23.4 \%$ & \\
\hline$>$ RWF10 000 & 251 & $36.0 \%$ & 282 & $40.3 \%$ & & 223 & $31.9 \%$ & 197 & $28.1 \%$ & \\
\hline Land ownership: & & & & & & & & & & \\
\hline Own land & 149 & $21.3 \%$ & 192 & $27.4 \%$ & 0.4 & 161 & $23.0 \%$ & 165 & $23.6 \%$ & 0.3 \\
\hline Rent land & 239 & $34.2 \%$ & 194 & $27.7 \%$ & & 239 & $34.1 \%$ & 247 & $35.3 \%$ & \\
\hline Own and rent & 245 & $35.1 \%$ & 250 & $35.7 \%$ & & 188 & $26.9 \%$ & 196 & $28.0 \%$ & \\
\hline Do not own or rent & 66 & $9.4 \%$ & 64 & $9.1 \%$ & & 112 & $16.0 \%$ & 92 & $13.1 \%$ & \\
\hline Home ownership & 595 & $85.1 \%$ & 597 & $85.4 \%$ & 0.9 & 589 & $84.0 \%$ & 567 & $81.0 \%$ & 0.3 \\
\hline Asset ownership: & & & & & & & & & & \\
\hline Radio & 397 & $57.0 \%$ & 336 & $48.0 \%$ & 0.1 & 338 & $48.0 \%$ & 303 & $43.0 \%$ & 0.4 \\
\hline Electricity & 158 & $23.0 \%$ & 96 & $14.0 \%$ & 0.2 & 227 & $32.0 \%$ & 174 & $25.0 \%$ & 0.2 \\
\hline Bicycle & 167 & $24.0 \%$ & 183 & $26.0 \%$ & 0.7 & 171 & $24.0 \%$ & 175 & $25.0 \%$ & 0.9 \\
\hline Cellphone & 504 & $72.0 \%$ & 456 & $65.0 \%$ & 0.1 & 483 & $69.0 \%$ & 457 & $65.0 \%$ & 0.3 \\
\hline Weighted asset score & & 7.1 & & 6.9 & 0.3 & & 7.2 & & 7.4 & 0.3 \\
\hline Earning disparity: & & & & & & & & & & \\
\hline About same & 69 & $6.7 \%$ & 96 & $5.4 \%$ & 1.0 & 64 & $9.2 \%$ & 87 & $12.4 \%$ & 0.5 \\
\hline All work together & 327 & $36.5 \%$ & 324 & $34.4 \%$ & & 239 & $34.2 \%$ & 281 & $40.1 \%$ & \\
\hline Husband more & 47 & $47.0 \%$ & 38 & $46.0 \%$ & & 300 & $43.0 \%$ & 283 & $40.4 \%$ & \\
\hline Wife more & 255 & $9.9 \%$ & 240 & $13.8 \%$ & & 95 & $13.6 \%$ & 49 & $7.0 \%$ & \\
\hline Hunger score & & 4.9 & & 4.9 & 0.8 & & 5.0 & & 5.0 & 0.6 \\
\hline Alcohol use: & & & & & & & & & & \\
\hline Seen male partner drunk & 354 & $68.0 \%$ & 358 & $71.0 \%$ & 0.6 & 386 & $75.0 \%$ & 339 & $69.0 \%$ & 0.3 \\
\hline Woman's alcohol use: & & & & & & & & & & \\
\hline None & 548 & $78.4 \%$ & 570 & $81.4 \%$ & 0.4 & 616 & $88.0 \%$ & 610 & $87.1 \%$ & 0.7 \\
\hline Any & 101 & $14.5 \%$ & 91 & $13.0 \%$ & & 55 & $7.9 \%$ & 57 & $8.1 \%$ & \\
\hline Alcohol problem/issue & 50 & $7.2 \%$ & 39 & $5.6 \%$ & & 29 & $4.1 \%$ & 33 & $4.7 \%$ & \\
\hline VSLA membership: & & & & & & & & & & \\
\hline I belong & 230 & $33.0 \%$ & 214 & $31.0 \%$ & 0.4 & 254 & $36.3 \%$ & 203 & $29.0 \%$ & 0.1 \\
\hline Spouse belongs & 119 & $17.0 \%$ & 104 & $15.0 \%$ & & 108 & $15.4 \%$ & 125 & $17.9 \%$ & \\
\hline Both & 199 & $29.0 \%$ & 221 & $32.0 \%$ & & 185 & $26.4 \%$ & 181 & $25.9 \%$ & \\
\hline None & 150 & $21.0 \%$ & 161 & $23.0 \%$ & & 153 & $21.9 \%$ & 191 & $27.3 \%$ & \\
\hline Previous experience of IPV: & & & & & & & & & & \\
\hline Physical & 25 & $27.0 \%$ & 23 & $20.0 \%$ & 0.3 & 37 & $40.0 \%$ & 27 & $30.0 \%$ & 0.1 \\
\hline Sexual & 56 & $8.0 \%$ & 52 & $7.0 \%$ & 0.8 & 39 & $41.0 \%$ & 21 & $22.0 \%$ & 0.0 \\
\hline Forced first sexual experience & 180 & $26.0 \%$ & 173 & $25.0 \%$ & 0.7 & 197 & $28.0 \%$ & 173 & $25.0 \%$ & 0.3 \\
\hline
\end{tabular}

$\mathrm{CI}$ - confidence interval, VSLA - village savings and loan associations, IPV - intimate partner violence 
Table 5. Descriptive data for male participants

\begin{tabular}{|c|c|c|c|c|c|c|c|c|c|c|}
\hline \multirow[b]{3}{*}{ Variables } & \multicolumn{5}{|c|}{ BASELINE } & \multicolumn{5}{|c|}{ EndunE } \\
\hline & \multicolumn{2}{|c|}{ Intervention } & \multicolumn{2}{|c|}{ Control } & \multirow[b]{2}{*}{ P-value } & \multicolumn{2}{|c|}{ Intervention } & \multicolumn{2}{|c|}{ Control } & \multirow[b]{2}{*}{ P-value } \\
\hline & $\mathrm{N}$ & $\%$ or mean & $\mathrm{N}$ & $\%$ or mean & & $\mathrm{N}$ & $\%$ or mean & $\mathrm{N}$ & $\%$ or mean & \\
\hline Age (years): & & & & & & & & & & \\
\hline$\leq 25$ & 55 & $7.9 \%$ & 47 & $6.7 \%$ & 0.3 & 41 & $5.9 \%$ & 58 & $8.3 \%$ & 0.4 \\
\hline $26-30$ & 138 & $19.7 \%$ & 174 & $24.9 \%$ & & 134 & $19.1 \%$ & 135 & $19.3 \%$ & \\
\hline $31-35$ & 195 & $27.9 \%$ & 188 & $26.9 \%$ & & 180 & $25.7 \%$ & 199 & $28.4 \%$ & \\
\hline $36-40$ & 134 & $19.1 \%$ & 154 & $22.0 \%$ & & 181 & $25.9 \%$ & 138 & $19.7 \%$ & \\
\hline$\geq 4$ & 178 & $25.4 \%$ & 137 & $19.6 \%$ & & 164 & $23.4 \%$ & 170 & $24.3 \%$ & \\
\hline Education: & & & & & & & & & & \\
\hline None & 116 & $17.0 \%$ & 125 & $18.0 \%$ & 0.7 & 139 & $19.9 \%$ & 128 & $18.3 \%$ & 0.6 \\
\hline Primary & 460 & $66.0 \%$ & 453 & $65.0 \%$ & & 451 & $64.4 \%$ & 458 & $65.5 \%$ & \\
\hline Secondary or above & 124 & $18.0 \%$ & 122 & $17.0 \%$ & & 110 & $15.7 \%$ & 113 & $16.2 \%$ & \\
\hline Marital status: & & & & & & & & & & \\
\hline Married & 461 & $66.0 \%$ & 424 & $69.0 \%$ & 0.3 & 418 & $59.7 \%$ & 376 & $53.7 \%$ & 0.3 \\
\hline Living as if married & 239 & $34.0 \%$ & 276 & $39.0 \%$ & & 282 & $40.3 \%$ & 324 & $46.3 \%$ & \\
\hline Polygamy: & & & & & & & & & & \\
\hline Yes & 32 & $4.6 \%$ & 41 & $5.9 \%$ & 0.2 & 45 & $6.4 \%$ & 40 & $5.7 \%$ & 0.6 \\
\hline No & 668 & $95.4 \%$ & 659 & $94.1 \%$ & & 655 & $93.6 \%$ & 660 & $94.3 \%$ & \\
\hline Children: & & & & & & & & & & \\
\hline None & 33 & $4.7 \%$ & 39 & $5.6 \%$ & 0.5 & 46 & $6.6 \%$ & 55 & $7.9 \%$ & 0.4 \\
\hline One & 109 & $15.6 \%$ & 90 & $12.9 \%$ & & 119 & $17.0 \%$ & 119 & $17.0 \%$ & \\
\hline Two & 142 & $20.3 \%$ & 173 & $24.7 \%$ & & 149 & $21.3 \%$ & 147 & $21.0 \%$ & \\
\hline Three & 130 & $18.6 \%$ & 139 & $19.9 \%$ & & 144 & $20.6 \%$ & 150 & $21.5 \%$ & \\
\hline Four or more & 286 & $40.9 \%$ & 259 & $37.0 \%$ & & 242 & $34.6 \%$ & 228 & $32.6 \%$ & \\
\hline Income: & & & & & & & & & & \\
\hline No cash & 220 & $31.0 \%$ & 238 & $34.0 \%$ & 0.8 & 207 & $29.6 \%$ & 187 & $26.7 \%$ & 0.6 \\
\hline$<$ RWF5000 & 273 & $39.0 \%$ & 268 & $38.3 \%$ & & 281 & $40.1 \%$ & 282 & $40.3 \%$ & \\
\hline RWF5001-10000 & 108 & $15.4 \%$ & 91 & $13.0 \%$ & & 122 & $17.4 \%$ & 132 & $18.9 \%$ & \\
\hline$>$ RWF10000 & 99 & $14.1 \%$ & 103 & $14.7 \%$ & & 90 & $12.9 \%$ & 99 & $14.1 \%$ & \\
\hline Debt in previous month: & & & & & & & & & & \\
\hline No debt & 109 & $15.6 \%$ & 109 & $15.6 \%$ & 0.4 & 88 & $12.6 \%$ & 133 & $19.0 \%$ & 0.0 \\
\hline$<$ RWF1000-2000 & 211 & $30.1 \%$ & 235 & $33.6 \%$ & & 247 & $35.3 \%$ & 243 & $34.8 \%$ & \\
\hline RWF2001-10000 & 175 & $25.0 \%$ & 161 & $23.0 \%$ & & 149 & $21.3 \%$ & 128 & $18.3 \%$ & \\
\hline$>$ RWF10000 & 205 & $29.3 \%$ & 195 & $27.9 \%$ & & 216 & $30.9 \%$ & 195 & $27.9 \%$ & \\
\hline Land ownership: & & & & & & & & & & \\
\hline Own land & 163 & $23.3 \%$ & 183 & $26.0 \%$ & 0.1 & 139 & $19.9 \%$ & 158 & $22.6 \%$ & 0.8 \\
\hline Rent land & 222 & $31.8 \%$ & 239 & $34.1 \%$ & & 249 & $35.6 \%$ & 237 & $33.9 \%$ & \\
\hline Own and rent & 251 & $35.9 \%$ & 209 & $29.9 \%$ & & 235 & $33.6 \%$ & 214 & $30.6 \%$ & \\
\hline Do not own or rent & 63 & $9.0 \%$ & 69 & $9.9 \%$ & & 76 & $10.9 \%$ & 91 & $13.0 \%$ & \\
\hline Home ownership & 613 & $88.0 \%$ & 603 & $86.0 \%$ & 0.5 & 621 & $88.0 \%$ & 589 & $84.0 \%$ & 0.1 \\
\hline Asset ownership: & & & & & & & & & & \\
\hline Radio & 432 & $61.7 \%$ & 383 & $54.7 \%$ & 0.1 & 396 & $57.0 \%$ & 388 & $55.0 \%$ & 0.8 \\
\hline Electricity & 140 & $20.0 \%$ & 115 & $16.0 \%$ & 0.6 & 197 & $28.0 \%$ & 210 & $30.0 \%$ & 0.8 \\
\hline Bicycle & 244 & $35.0 \%$ & 210 & $30.0 \%$ & 0.5 & 220 & $31.0 \%$ & 182 & $26.0 \%$ & 0.4 \\
\hline Cell phone & 506 & $72.0 \%$ & 496 & $71.0 \%$ & 0.7 & 522 & $75.0 \%$ & 494 & $71.0 \%$ & 0.2 \\
\hline Weighted Asset Score & & 7.5 & & 6.9 & 0.3 & & 7.6 & & 7.39 & 0.3 \\
\hline Earning disparity: & & & & & & & & & & \\
\hline About same & 193 & $28.0 \%$ & 172 & $24.6 \%$ & 0.4 & 160 & $22.9 \%$ & 152 & $21.8 \%$ & 0.6 \\
\hline All work together & 83 & $6.2 \%$ & 74 & $7.5 \%$ & & 71 & $10.1 \%$ & 70 & $10.0 \%$ & \\
\hline Husband more & 43 & $11.9 \%$ & 52 & $10.6 \%$ & & 97 & $13.9 \%$ & 87 & $12.5 \%$ & \\
\hline Wife more & 378 & $54.2 \%$ & 400 & $57.3 \%$ & & 372 & $53.1 \%$ & 390 & $55.8 \%$ & \\
\hline Hunger score & & 5.0 & & 5.1 & 0.5 & & 4.9 & & 5.0 & 0.6 \\
\hline Alcohol use: & & & & & & & & & & \\
\hline None & 393 & $56.1 \%$ & 484 & $69.1 \%$ & $<0.001$ & 407 & $58.1 \%$ & 429 & $61.3 \%$ & 0.3 \\
\hline Any & 205 & $29.3 \%$ & 156 & $22.3 \%$ & & 180 & $25.7 \%$ & 187 & $26.7 \%$ & \\
\hline Alcohol problem/issue & 102 & $14.6 \%$ & 60 & $8.6 \%$ & & 113 & $16.1 \%$ & 84 & $12.0 \%$ & \\
\hline VSLA membership: & & & & & & & & & & \\
\hline I belong & 186 & $27.0 \%$ & 189 & $27.0 \%$ & 0.6 & 144 & $20.6 \%$ & 144 & $20.6 \%$ & 0.8 \\
\hline Spouse belongs & 140 & $20.0 \%$ & 134 & $19.0 \%$ & & 158 & $22.6 \%$ & 184 & $26.3 \%$ & \\
\hline Both & 233 & $33.0 \%$ & 214 & $31.0 \%$ & & 256 & $36.6 \%$ & 215 & $30.7 \%$ & \\
\hline None & 140 & $20.0 \%$ & 163 & $23.0 \%$ & & 142 & $20.3 \%$ & 157 & $22.4 \%$ & \\
\hline Physical IPV against previous partner & 76 & $10.9 \%$ & 59 & $8.0 \%$ & 0.2 & 69 & $25.0 \%$ & 43 & $16.0 \%$ & 0.1 \\
\hline Sexual IPV against previous partner & 27 & $4.0 \%$ & 30 & $4.0 \%$ & 0.7 & 36 & $12.0 \%$ & 31 & $10.0 \%$ & 0.4 \\
\hline Witnessed mothers' abuse as a child & 324 & $46.0 \%$ & 289 & $41.0 \%$ & 0.2 & 347 & $50.0 \%$ & 322 & $46.0 \%$ & 0.4 \\
\hline Physically abused as a child: & & & & & & & & & & \\
\hline Never/sometimes & 491 & $70.0 \%$ & 460 & $66.0 \%$ & 0.2 & 431 & $61.6 \%$ & 440 & $62.9 \%$ & 0.8 \\
\hline Often & 132 & $19.0 \%$ & 151 & $22.0 \%$ & & 160 & $22.9 \%$ & 147 & $21.0 \%$ & \\
\hline Very often & 77 & $11.0 \%$ & 89 & $13.0 \%$ & & 109 & $15.6 \%$ & 113 & $16.1 \%$ & \\
\hline
\end{tabular}

VSLA - village savings and loan associations, IPV -intimate partner violence 
both baseline and endline. Men ranged in age from 19 to 51 years with roughly half between 26 and 35 years old in both intervention and control communities. Two thirds of both female and male participants had completed primary school and were formally married, in both cross-sectional samples.

\section{Primary outcomes}

Multivariate results for women and men are presented in Table 6 and Table 7. Among women, there was no significant difference between participants in the intervention and control communities in change over time of experiencing physical and/or sexual IPV from a current male partner in the past 12 months. The adjusted odds ratio (aOR) for the intervention impact on self-reported experience of IPV was aOR $=1.25$ (95\% CI =0.92-1.70, P=0.16). Likewise, there was no difference in change over time in self-reported rates of perpetration of physical and/or sexual IPV among male participants in the treatment and control groups $(\mathrm{aOR}=1.02 ; 95 \% \mathrm{CI}=0.72-1.45, \mathrm{P}=0.89)$.

Similarly, there were no significant difference in scores for the acceptability of wife beating at a population level among either female $(\beta=0.04,95 \% \mathrm{CI}=-0.23-0.31, P=0.77)$ or male $(\beta=0.09,95 \% \mathrm{CI}=-0.10$ $0.29, P=0.34)$ participants in the control or treatment groups over time. Neither was there evidence of an increase in the support offered to victims of gender-based violence in the intervention or control sectors among female $\beta=-0.09(95 \% \mathrm{CI}=-0.61-0.44, P=0.75)$ and male $\beta=-0.13(95 \% \mathrm{CI}=-0.65-0.40$, $P=0.64)$ participants.

Thus, we were unable to reject the null hypothesis of no intervention impact.

Table 6. Multivariate results for all women

\begin{tabular}{|c|c|c|c|c|c|c|c|}
\hline & \multirow{2}{*}{ StudY ARM } & \multirow{2}{*}{$\begin{array}{l}\text { BASELINE } \% \\
\text { OR MEAN }\end{array}$} & \multirow{2}{*}{$\begin{array}{l}\text { ENDLINE } \% \\
\text { OR MEAN }\end{array}$} & \multirow{2}{*}{ coeff } & \multicolumn{2}{|c|}{$95 \%$ CI } & \multirow{2}{*}{ P-value } \\
\hline & & & & & lower & upper & \\
\hline \multicolumn{8}{|l|}{ Primary outcomes: } \\
\hline \multirow[t]{2}{*}{ Physical and/or sexual intimate partner violence with main partner } & Control & $50.9 \%$ & $49.7 \%$ & & & & \\
\hline & Intervention & $58.9 \%$ & $63.1 \%$ & 1.25 & 0.92 & 1.70 & 0.16 \\
\hline \multirow[t]{2}{*}{$\begin{array}{l}\text { Acceptability of wife beating (number of reasons endorsed as justifications, } \\
\text { range 0-5) }\end{array}$} & Control & 2.40 & 2.50 & & & & \\
\hline & Intervention & 2.00 & 2.20 & 0.04 & -0.23 & 0.31 & 0.77 \\
\hline \multirow[t]{2}{*}{$\begin{array}{l}\text { Actions to support victims of gender-based violence or combat gender-based } \\
\text { violence (range 0-12) }\end{array}$} & Control & 7.10 & 6.70 & & & & \\
\hline & Intervention & 7.10 & 6.60 & -0.09 & -0.61 & 0.44 & 0.75 \\
\hline \multicolumn{8}{|l|}{ Secondary outcomes: } \\
\hline \multirow[t]{2}{*}{ Sources of information on IPV and number of times heard (range 0-36) } & Control & 19.90 & 20.20 & & & & \\
\hline & Intervention & 21.00 & 21.10 & -0.04 & -1.41 & 1.33 & 0.96 \\
\hline \multirow[t]{2}{*}{ Help seeking among survivors of IPV ( $\mathrm{N}=872$ baseline, $\mathrm{N}=933$ endline) } & Control & $54.3 \%$ & $51.8 \%$ & & & & \\
\hline & Intervention & $55.1 \%$ & $56.7 \%$ & 1.15 & 0.79 & 1.68 & 0.46 \\
\hline \multicolumn{8}{|l|}{ Other outcomes measures (exploratory): } \\
\hline \multirow[t]{2}{*}{ Physical intimate partner violence, main partnership } & Control & $40.9 \%$ & $41.9 \%$ & & & & \\
\hline & Intervention & $49.6 \%$ & $56.7 \%$ & 1.27 & 0.93 & 1.73 & 0.13 \\
\hline \multirow[t]{2}{*}{ Forced or coerced sex with main partner } & Control & $46.0 \%$ & $43.8 \%$ & & & & \\
\hline & Intervention & $50.5 \%$ & $55.6 \%$ & 1.35 & 0.99 & 1.82 & 0.06 \\
\hline \multirow[t]{2}{*}{ Economic abuse with main partner } & Control & $49.1 \%$ & $53.6 \%$ & & & & \\
\hline & Intervention & $52.1 \%$ & $64.0 \%$ & 1.36 & 1.00 & 1.85 & 0.05 \\
\hline \multirow[t]{2}{*}{ Emotional aggression with main partner } & Control & $71.9 \%$ & $73.8 \%$ & & & & \\
\hline & Intervention & $78.5 \%$ & $82.3 \%$ & 1.16 & 0.81 & 1.66 & 0.43 \\
\hline \multicolumn{8}{|l|}{ Children in household witnessing IPV } \\
\hline \multirow[t]{2}{*}{$\begin{array}{l}\text { ( } \mathrm{N}=798 \text { baseline, } \mathrm{N}=786 \mathrm{control} \text { household with children under 18, who } \\
\text { reported physical or sexual IPV, and did not respond "don't know" regard- } \\
\text { ing child witnessing) }\end{array}$} & Control & $46.5 \%$ & $47.3 \%$ & & & & \\
\hline & Intervention & $46.2 \%$ & $54.6 \%$ & 1.29 & 0.86 & 1.94 & 0.22 \\
\hline \multirow[t]{2}{*}{ Support for women working outside the home (range -4 to +4 ) } & Control & 1.33 & 1.42 & & & & \\
\hline & Intervention & 1.24 & 1.25 & -0.09 & -0.40 & 0.21 & 0.54 \\
\hline \multirow[t]{2}{*}{ Change in strategies used to address IPV (range 0-12) } & Control & 3.17 & 2.98 & & & & \\
\hline & Intervention & 3.23 & 3.56 & 0.50 & -0.13 & 1.13 & 0.12 \\
\hline
\end{tabular}

aOR - adjusted odds ratio, $\mathrm{CI}$ - confidence interval, IPV - intimate partner violence

*All models control for age, education, and asset score. 
Table 7. Multivariate results for all men*

\begin{tabular}{|c|c|c|c|c|c|c|c|}
\hline & \multirow{2}{*}{ Study ARM } & \multirow{2}{*}{$\begin{array}{l}\text { BASELINE } \% \\
\text { OR MEAN }\end{array}$} & \multirow{2}{*}{$\begin{array}{l}\text { ENDLINE } \% \text { OR } \\
\text { MEAN }\end{array}$} & \multirow{2}{*}{ coeff } & \multicolumn{2}{|c|}{$95 \%$ CI } & \multirow{2}{*}{$P_{\text {-value }}$} \\
\hline & & & & & lower & upper & \\
\hline \multicolumn{8}{|l|}{ Primary outcomes: } \\
\hline \multirow[t]{2}{*}{ Physical and/or sexual intimate partner violence with main partner } & Control & $19.7 \%$ & $21.4 \%$ & & & & \\
\hline & Intervention & $31.7 \%$ & $34.7 \%$ & 1.02 & 0.72 & 1.45 & 0.89 \\
\hline \multirow[t]{2}{*}{$\begin{array}{l}\text { Acceptability of wife beating (number of reasons endorsed as justifications, } \\
\text { range 0-5) }\end{array}$} & Control & 0.92 & 0.91 & & & & \\
\hline & Intervention & 0.92 & 1.03 & 0.09 & -0.10 & 0.29 & 0.34 \\
\hline \multirow[t]{2}{*}{$\begin{array}{l}\text { Actions to support victims of gender-based violence or combat gender-based } \\
\text { violence (range 0-12) }\end{array}$} & Control & 7.72 & 7.58 & & & & \\
\hline & Intervention & 7.60 & 7.29 & -0.13 & -0.65 & 0.40 & 0.64 \\
\hline \multicolumn{8}{|l|}{ Secondary outcomes: } \\
\hline \multirow[t]{2}{*}{ Sources of information on IPV and number of times heard (range 0-36) } & Control & 20.4 & 21.9 & & & & \\
\hline & Intervention & 21.3 & 22.0 & -0.70 & -2.15 & 0.76 & 0.35 \\
\hline \multicolumn{8}{|l|}{ Other outcomes measures (exploratory): } \\
\hline \multirow[t]{2}{*}{ Physical intimate partner violence, main partnership } & Control & $22.5 \%$ & $24.1 \%$ & & & & \\
\hline & Intervention & $30.2 \%$ & $35.5 \%$ & 1.14 & 0.81 & 1.61 & 0.44 \\
\hline \multirow[t]{2}{*}{ Forced or coerced sex with main partner } & Control & $16.7 \%$ & $17.3 \%$ & & & & \\
\hline & Intervention & $27.3 \%$ & $29.8 \%$ & 1.08 & 0.74 & 1.55 & 0.70 \\
\hline \multirow[t]{2}{*}{ Economic abuse with main partner } & Control & $33.2 \%$ & $34.1 \%$ & & & & \\
\hline & Intervention & $34.6 \%$ & $40.9 \%$ & 1.23 & 0.90 & 1.69 & 0.19 \\
\hline Children in household witnessing IPV & Control & & & & & & \\
\hline \multirow[t]{2}{*}{$\begin{array}{l}\text { ( } N=470 \text { baseline, } N=476 \text { household with children under 18, who report- } \\
\text { ed physical or sexual IPV, and did not respond "don't know" regarding child } \\
\text { witnessing) }\end{array}$} & & $31.7 \%$ & $28.7 \%$ & & & & \\
\hline & Intervention & $32.8 \%$ & $40.1 \%$ & 1.66 & 0.93 & 2.94 & 0.09 \\
\hline \multirow[t]{2}{*}{ Support for women working outside the home (range -4 to +4$)$} & Control & 0.97 & 0.84 & & & & \\
\hline & Intervention & 0.96 & 0.74 & -0.12 & -0.43 & 0.19 & 0.45 \\
\hline
\end{tabular}

aOR - adjusted odds ratio, CI - confidence interval, IPV - intimate partner violence

*All models control for age, education, and asset score.

\section{Secondary outcomes}

There were no significant difference in scores for the sources of information on IPV and number of times heard at a population level among either female $(\beta=-0.04,95 \% \mathrm{CI}=-1.41-1.33, P=0.96)$ or male $(\beta=-0.70,95 \% \mathrm{CI}=-2.15-0.76, P=0.35)$ participants in the control or treatment groups over time. Among women, there were also no detectable differences in help seeking among victims living in the intervention compared to control communities ( $\mathrm{aOR}=1.15 ; 95 \% \mathrm{CI}=0.79-1.68 \mathrm{P}=0.46)$.

\section{Exploratory outcomes}

We found no evidence of a significant difference among women in the intervention and control communities in change over time in the experience of physical ( $\mathrm{aOR}=1.27 ; 95 \% \mathrm{CI}=0.93-1.73, P=0.13$ ) or emotional IPV $(\mathrm{aOR}=1.16 ; 95 \% \mathrm{CI}=0.81-1.66, \mathrm{P}=0.43)$ from a current male partner in the past 12 months. Among women, there was weak evidence of potential increased reporting of sexual IPV over time for the intervention group compared to the control group ( $\mathrm{aOR}=1.35,95 \% \mathrm{CI}=0.99-1.82, \mathrm{P}=0.06$ ). There was no significant difference, however, in the reporting of perpetration of sexual IPV by male (aOR $=1.08$, $95 \% \mathrm{CI}=0.74-1.55, P=0.70)$ participants in the control vs treatment groups over time. Women in the treatment group likewise reported more economic violence over time than those in the control group $(\mathrm{aOR}=1.36,95 \% \mathrm{CI}=1.00-1.85, P=0.05)$. We did not find any evidence of an increase in the reporting of perpetration of economic IPV between men in the treatment and control groups over time $(\mathrm{aOR}=1.23$, $95 \% \mathrm{CI}=0.90-1.69, P=0.19)$.

We also tested for differences among participants in the control and treatment groups for a range of other exploratory outcomes including support for women's participation in the laborforce, children witnessing IPV, and change in strategies used to support individuals experiencing IPV. We did not find any statistically significant differences in any of these outcomes, whether reported by female or male participants.

Despite the lack of a measurable community-level effect of the activism activities on IPV, both survey and qualitative data suggest that the women's safe spaces were generally well utilised and regarded by com- 
munities. Table 8 shows the number of people who were attending the women's spaces and accessing services. The fact that $92.8 \%$ of women and $96.2 \%$ of men were aware of the service and were willing to recommend it to others speaks to the excellent reputation of the safe spaces across intervention communities. Moreover, the majority of those who reported attending activities or seeking services at the women's spaces did so more than once.

\section{Process evaluation findings}

The process evaluation data suggests several potential reasons why the activism component of Indashyikirwa failed to reduce IPV at a community level, specifically problems applying the SASA!'s style of "informal activism" to the Rwandan context; unanticipated delays in rolling out the activism component of the programme; and confusion over the notion of "phasing" - a concept central to the SASA! theory of change.

\section{Challenges in cultural adaptation}

A core concept of the SASA! approach to community mobilisation is the notion of "informal" activism - engaging community members in conversation where they congregate: at moto stands, local repair shops or local markets. Process evaluation data suggest that this type of "informal activism" did not translate easily to the Rwandan setting, where more formal settings are the norm [13]. Indeed, many CAs and program staff reflected on how community members did not feel comfortable discussing intimate matters in public:

"Rwandans are not used to discuss their issue in public. You need to choose a safer place to help people gain their trust. On the side of the road or at a market it will be hard." (RWAMREC Field Supervisor, Western Province).

CAs found that participants preferred to enagage in more formal environments. Because of this, activists used existing forums, such as parents evening forums, umuganda, and VSLA groups to deliver their messages [23]. This likely limited the diffusion of program content, especially if the same individuals attended these events over time. Indeed, one supervisor expressed concern that their monitoring data likely double counted beneficiaries since CAs returned multiple times to the same community forms:

"We don't know how many people we met, how many people got the message in a month. We only have these VSLs, village meetings, we don't have many opportunities... One activist may go to a VSL and meet 15 people, and the next day another activist goes to the same VSL. We meet the same people because we don't have enough opportunities to meet people." (RWAMREC Field Supervisor, Eastern Province)

Such forums can have a large amount of attendees and as a result, often demand a more didactic style of communication than the interactive engagement anticipated by the SASA! model. CAs observed that when facilitating activism at government led initiatives, they were frequently only afforded 5 minutes or less by opinion leaders at the end of a meeting to impart their message. This challenge was helpfully ad-

Table 8. Findings from women's safe spaces

\begin{tabular}{|c|c|c|c|c|c|c|c|c|c|c|}
\hline \multirow[b]{3}{*}{ Variables } & \multicolumn{5}{|c|}{ ALL RESPONDENTS } & \multicolumn{5}{|c|}{ THOSE WHO HAD HEARD OF WOMEN'S SPACES } \\
\hline & \multicolumn{2}{|c|}{ Women } & \multicolumn{2}{|c|}{ Men } & \multirow[b]{2}{*}{$P$-value } & \multicolumn{2}{|c|}{ Women } & \multicolumn{2}{|c|}{ Men } & \multirow[b]{2}{*}{$\boldsymbol{P}$-value } \\
\hline & $\mathrm{N}$ & $\%$ & $\mathrm{~N}$ & $\%$ & & $\mathrm{~N}$ & $\%$ & $\mathbf{N}$ & $\%$ & \\
\hline \multicolumn{11}{|c|}{ Have you ever heard about the women space? (out of $\mathrm{N}=700$ women and $\mathrm{N}=700$ men interviewed in intervention communities) } \\
\hline & 483 & $69.00 \%$ & 497 & $71.00 \%$ & 0.63 & & N/A & & N/A & N/A \\
\hline \multicolumn{11}{|c|}{ Have you ever been involved in the activities of the women's space? } \\
\hline Yes, once & 86 & $12.30 \%$ & 93 & $13.30 \%$ & 0.44 & 100 & $20.70 \%$ & 86 & $17.30 \%$ & 0.07 \\
\hline Yes, twice & 89 & $12.70 \%$ & 77 & $11.00 \%$ & & 89 & $18.40 \%$ & 77 & $15.50 \%$ & \\
\hline Yes, more than twice & 170 & $24.30 \%$ & 162 & $23.10 \%$ & & 170 & $35.10 \%$ & 162 & $32.50 \%$ & \\
\hline Total & 345 & $49.30 \%$ & 332 & $47.40 \%$ & & 358 & $74.20 \%$ & 325 & $65.30 \%$ & \\
\hline \multicolumn{11}{|c|}{ Have you sought assistance from the women's space for problems you were having? } \\
\hline Yes, once & 74 & $10.60 \%$ & 78 & $11.10 \%$ & 0.47 & 74 & $15.30 \%$ & 78 & $15.70 \%$ & 0.44 \\
\hline Yes, twice & 31 & $4.40 \%$ & 35 & $5.00 \%$ & & 31 & $6.40 \%$ & 35 & $7.00 \%$ & \\
\hline Yes, more than twice & 38 & $5.40 \%$ & 53 & $7.60 \%$ & & 38 & $7.90 \%$ & 53 & $10.60 \%$ & \\
\hline Total & 143 & $20.40 \%$ & 166 & $23.70 \%$ & & 142 & $29.50 \%$ & 166 & $33.30 \%$ & \\
\hline \multicolumn{11}{|c|}{ Are you aware of anyone else who has sought service from the women's space? } \\
\hline & 253 & $36.10 \%$ & 303 & $43.30 \%$ & 0.08 & 253 & $52.40 \%$ & 303 & $61.00 \%$ & 0.01 \\
\hline \multicolumn{11}{|c|}{ Would you advise other women to seek assistance from the women's space? } \\
\hline & 450 & $64.30 \%$ & 479 & $68.40 \%$ & 0.34 & 448 & $92.80 \%$ & 478 & $96.20 \%$ & 0.06 \\
\hline
\end{tabular}


dressed through RWAMREC staff emphasizing to local leaders the importance of CAs having more time to facilitate their activities, and through leaders increasingly recognizing the value of the activism efforts.

Indeed, there was much discussion on behalf of CAs and staff describing how the participatory approaches to facilitation and dialogue anticipated by SASA! were a novel approach for many CAS, and it took effort to help them feel more comfortable with and have opportunities for this model.

"The [CAs] do not do informal activism. We push them to go to markets, churches, bus stations, but they are shy. They don't dare go there. When we ask local leaders or pastors, they say we have these opportunities, but when we ask community acitivists to go there, they are still shy. I think this is related to the new approach because Rwandans are not familiar with this kind of thing. At first people were scared to talk in public but there is improvement, slowly." (RWAMREC Field Supervisor, Eastern Province).

Although this engagement eventually evolved into opportunities for participatory discussions with smaller groups, this process took considerable time, which likely compromised the programme's potential impact. It would have been beneficial to have modified the SASA! model and piloted the cultural modifications before conducting a cRCT.

\section{Shortened implementation}

Data from monitoring interviews with project managers and field staff, and observations of CAs and women's space facilitators, likewise confirm that the time available for activism was trunctated, likely limiting the programme's ability to achieve its objectives. Because of the time required to finalise the Indashyikirwa design, pilot and implement the couple's curricula, and adapt SASA! activist materials to the Rwandan setting, Indashyikirwa only had 1.5 years available for activism (November 2016-June 2018). The SASA! fidelity brief suggests that a minimum of 3 to 5 years of community mobilisation is necessary to shift norms and reduce IPV [18].

Programme implementation also encountered various delays that ate into the time available for community mobilisation. Community activists were delayed in the first instance because not all village leaders were initially briefed about the program or involved in the opinion leader training [23]. Introductions to the programme were originally held at the sector level, rather than the cell or village level; this meant that many village heads had not been briefed when activists began their activities. This proved especially problematic because village heads served as critical gatekeepers to many of the formal community structures, such as domestic violence committees and parenting forums, that CAs initially relied upon. Without support from the village head, community activists did not feel comfortable or able to facilitate activism. As one field officer reflected:

The need to gain support from village leaders necessitated an additional (and unanticipated) round of project introductions by program staff throughout the fourteen sectors before activism activities could get under way.

Program partners universally reported that the activism component of Indashyikirwa was far too rushed [23] and that community members did not have adequate time to internalise and apply the more advanced concepts of SASA! focused on encouraging norm change and taking action against violence.

"I don't think we have enough time for activism. It is not long enough. Skipping from this phase to the other, I think it should require a certain long time. If we are copying SASA!, we are a bit squeezed for time." (RWAMREC Field Officer)

Some activists lamented not having a diversity of materials earlier on:

"The images are not enough. There are some groups where we finished all of the images and now, we go back with them again." (Male Activist 01 Western Province)

"Also, in this village, they now know many things and sometimes when we are going to discuss on a certain image, they say: "no, it has been a long time since we studied that image, let us discuss about that other one." (Male Activist 01 Eastern Province)

Despite these challenges, activists noted the changes in participants' understanding of positive and negative types of power and different types of IPV (physical, sexual, emotional and economic) during the start and awareness phases, as this content was emphasised through the activism materials and messages:

"What I like to tell the community people about forced sexual intercourse is that, that is not good. For example, when a husband came home being drunk, he used to force his wife to go to bed for sexual intercourse. We have talked with women, now many women have understood what violence is." (Male Activist 01 Western Province) 


\section{Phasing and diffusion}

In addition to cultural discordance and delays, the opportunity for deeper transformation was further complicated by lack of clarity around the notion of phasing - a core concept of SASA!'s theory of change. Each phase of SASA! focuses on a different outcome: start (knowledge), awareness (attitude), support (skills), action (behavior). In SASA!, monitoring and evaluation tools are used to assess progress through the phases and at the end of each phase, a Rapid Assessment Survey helps determine if "the community is ready to move to the next phase [18]."

Phased programming was a new and unfamiliar concept for the partners, and it was difficult to anticipate both when to move onto the next phase, as well as the effort required to do so [23]. There was a lack of consensus among field officers about when and how to encourage activists to move on in their activities. Notably, field officers did not receive sufficient training in the phased aspect of the programming and delivery of relevant messages:

"Field staff did not have a clear map that Phase I should go for this period, and then Phase 2 should be this long. Phase 1 and 2 was way longer and we were at the end of the project and we had to combine Phase 3 and 4. We did not know how to handle the phases and it was not mapped during our initial training". (RWAMERC Field Supervisor)

"It was not easy for staff to get the hang of how the activism was meant to happen. Moving from one phase to another... One of the things was depending on the understanding of the field officers, we had certain places where activism was working better than in other places... Some of them did not know what to do with the posters, and when to use them." (CARE Field Officer)

This uncertainty may have contributed to delays in encouraging and reinforcing activities around supporting victims and taking action to prevent violence-both important secondary outcomes for Indashyikirwa's community programme.

\section{DISCUSSION}

This study assessed the impact of the community activism component of the Indashyikirwa program on the prevention of IPV in a community sample. The process evaluation suggests that the overall lack of effect may have been due to implementation challenges. Even under the best conditions, it is rare for programmes to demonstrate significant reductions in IPV at a population level; only three trials (SASA!, SHARE, and the COMBAT in Ghana) have done so thus far $[3,6,7]$.

The SASA! fidelity brief suggests that 3-5 years of activist activity is required for phased implementation and activism to cover the required content necessary to shift norms and effect behavior change at a population level [18]. A core feature of SASA! is that it is designed to be implemented in phases, with content and support material rolled out over time. In Indashyikirwa, the Start and Awareness phase of SASA! were condensed into one (lasting roughly 16 months) and the third and fourth phases were similarly combined, with the materials for the Support and Action phases only made available in April 2018, 3 months before the evaluation endline. Most activists therefore relied largely on a few materials from the "start" and "awareness" phase of SASA!, which focused on introducing the four types of power (a key SASA! concept) and awareness of different types of violence.

While the time squeeze was due in part to avoidable delays, it also was a function of the time it takes to develop and pilot new interventions and adapt existing ones to new cultural settings. In our experience, donors currently underestimate the time it takes to undertake these activities responsibly and with rigor. To ensure project success, program planners and donors must allow sufficient time to accommodate all phases of program design and implementation as well as unexpected (but typical) programme delays. Future programmes of this complexity should be funded and evaluated over 5 to 7 years to ensure a fair assessment of project impact.

Our experience with Indashyikirwa further suggests that evidence based practices (EBP) need to be modified to suit the cultural needs of new communities, especially regarding the complexity of community processes [23-25]. The informal activism that was successful in urban Uganda did not easily translate easily to the highly organised structure of rural Rwanda. In their evaluation of the SASA! model, Starmann et al. [5] found that interpersonal communication was critical to the overall success of SASA! Rwandan CA's initial reliance on formal structures, such as umuganda, limited opportunities for reflection and interpersonal exchange. Many staff and activists nonetheless noted that home visits and couple to couple sharing emerged as highly successful strategies for diffusing programme content over time [23]. Thoughtful ad- 
aptation of programmes requires adjusting the means to achieve programme ends, rather than slavishly adhering to a given strategy.

The Indashyikirwa experience likewise raises questions about the degree to which phasing should be taken as central to the success of community mobilisation approaches to violence reduction. In SASA!, phasing serves two purposes: it allows activists to be trained in stages and ensures that community members grasp key concepts before moving onto new ones. It is yet unclear whether the benefits of allowing knowledge and attitude change to consolidate prior to encouraging action outweigh the potential confusion and delay caused by postponing action. Indeed, the designers of SASA! have modified this element in their newly released programme known as SASA Together (L. Michau, personal communication, October 25, 2019). SASA Together retains the notion of phasing but identifies a Knowledge, Feeling and Action goal for each phase. At the very least, the Rwandan experience highlights the importance of thoroughly orienting field staff to the logic and mechanics of phasing so that confusion does not hinder progress.

Our findings also raise the possibility that as implemented, the Indashyikirwa activist programme may have increased reporting of IPV among women, especially forced sex and economic violence by an intimate partner. Although, none of the point estimates achieved our pre-specificed level of significance of $P<0.05$, the estimates were uniformly above 1 and there was marginal evidence that reporting of sexual $(\mathrm{aOR}=1.35,95 \% \mathrm{CI}=0.99-1.82, P=0.06)$ and economic violence $(\mathrm{aOR}=1.36,95 \% \mathrm{CI}=1.00-1.85$, $P=0.05$ ) increased over time. Longitudinal analysis of the qualitative couple data in intervention communities indicates that both women and men were more likely to acknowledge sexual violence in their relationships over time [26], and higher levels of reported IPV overall would be consistent with the programmes'achieved emphasis on awareness raising, vs later stages of the SASA! change model.

In conclusion, community mobilisation strategies as a means to reduce levels of IPV deserve further investigation in rural Rwanda and in other rural settings. Consideration should be given up front into how best to encourage interpersonal reflection and collective action to transform norms and practices on gender, power and violence. Implementing agencies and donors should use the Indashyikirwa community component as an object lesson for the importance of cultural adapatation, adequate training and length of implementation.

As with all projects, this impact evaluation has a number of limitations. First, all measures rely on self-report which means they are subject to under-reporting and disclosure bias. There may also be social desirability bias around participants wanting to report favorably on an intervention they clearly valued or wanting to emphasise what they learned. We attempted to mitigate this strategy through offering the use of ACASI data collection. Evidence suggests that ACASI encourages more truthful and forthcoming reporting for stigmatised topics $[27,28]$. We also attempted to mitigate social desirability effects by using field researchers who were external to the program, specially trained in gender sensitivity, and emphasising the confidentiality of all answers.

The evaluation also had limited means to evaluate individual-level exposure to project activities. We chose to ask participants about past-year exposure to IPV messaging via a range of interpersonal, social, and communication channels at both baseline and endline, hypothesising that Indashyikirwa's sector-level activites would increase overall exposure. However, self-reported exposure to messaging was very high at baseline, leaving little room for movement, and the use of ACASI made it difficult at endline to assess exposure to messaging originating from Indashyikirwa vs other sources, although we do know that exposure to the women's safe spaces did not impact reports of IPV (data not shown). We strongly recommend that when assessing tradeoffs in data collection strategies, future studies find ways to both quantitively and qualitatively explore individual-level exposure to programme-specific activites and content of messages received. Such data will be valuable for both process evaluation and interpetation of impact evaluations, especially in the case of null findings at the community-level.

\section{CONCLUSION}

Although this study did not demonstrate violence reduction at the community level, it affirms the importance of program design and careful adaptation of EBPs to ensure fidelity and cultural appropriateness, and the importance of budgeting sufficient time for mobilisation activities before undertaking endline assessment. Failure to do so undermines the value of investing in rigorous randomised evaluations. This study also reinforces the value of embedded process evaluations, especially around the complex phenomenon of community activism and organised diffusion. We strongly recommended that all impact evaluations of violence interventions include both quantitative and qualitative components, preferably collecting both types of data repeatedly when possible. 
Acknowledgments: The trial was conducted as part of the What Works to Prevent Violence? A Global Programme on Violence against Women and Girls (VAWG) funded by the UK Government's Department for International Development (DFID). We also wish to acknowledge the input and support from the implementing partners: CARE International, Rwanda; RWARMEC; and RWN, as well as the participants who shared their experiences with us.

Author contributions: LH and KD conceptualised the project. KD planned and oversaw quantitative data collection; ES planned and oversaw qualitative data collection; LH gave input on all aspects of design and field work. SC and KD conducted the quantitative analysis and ES conducted the qualitative analysis; LH gave input on all analyses. SC and ES drafted the manuscript with input from KD and LH. All authors read and approved the final manuscript.

Competing interests: The authors completed the Unified Competing Interest form at www.icmje.org/coi_disclosure. pdf (available upon request from the corresponding author), and declare no conflicts of interest.

1 Devries KM, Mak JYT, García-Moreno C, Petzold M, Child JC, Falder G, et al. The Global Prevalence of Intimate Partner Violence Against Women. Science. 2013;340:1527-8. Medline:23788730 doi:10.1126/science.1240937

2 Cislaghi B, Denny EK, Cissé M, Gueye P, Shrestha B, Shrestha PN, et al. Changing Social Norms: the Importance of "Organized Diffusion" for Scaling Up Community Health Promotion and Women Empowerment Interventions. Prev Sci. 2019;20:936-46. Medline:30747395 doi:10.1007/s11121-019-00998-3

3 Wagman JA, Gray RH, Campbell JC, Thoma M, Ndyanabo A, Ssekasanvu J, et al. Effectiveness of an integrated intimate partner violence and HIV prevention intervention in Rakai, Uganda: analysis of an intervention in an existing cluster randomised cohort. Lancet Glob Health. 2015;3:e23-33. Medline:25539966 doi:10.1016/S2214-109X(14)70344-4

4 Hossain M, Zimmerman C, Kiss L, Kone D, Bakayoko-Topolska M, Manan DKA, et al. Men's and women's experiences of violence and traumatic events in rural Cote d'Ivoire before, during and after a period of armed conflict. BMJ Open. 2014;4:e003644. Medline:24568959 doi:10.1136/bmjopen-2013-003644

5 Starmann E, Heise L, Kyegombe N, Devries K, Abramsky T, Michau L, et al. Examining diffusion to understand the how of SASA! a violence against women and HIV prevention intervention in Uganda. BMC Public Health. 2018;18:616. Medline:29751754 doi:10.1186/s12889-018-5508-4

6 Kyegombe N, Starmann E, Devries KM, Michau L, Nakuti J, Musuya T, et al. 'SASA! is the medicine that treats violence'. Qualitative findings on how a community mobilisation intervention to prevent violence against women created change in Kampala, Uganda. Glob Health Action. 2014;7:25082. Medline:25226421 doi:10.3402/gha.v7.25082

7 Abramsky T, Devries K, Kiss L, Nakuti J, Kyegombe N, Starmann E, et al. Findings from the SASA! Study: a cluster randomized controlled trial to assess the impact of a community mobilization intervention to prevent violence against women and reduce HIV risk in Kampala, Uganda. BMC Med. 2014;12:122. Medline:25248996 doi:10.1186/s12916014-0122-5

8 Hatcher AM, Stöckl H, McBride R-S, Khumalo M, Christofides N. Pathways from food insecurity to intimate partner violence perpetration among peri-urban men in South Africa. Am J Prev Med. 2019;56:765-72. Medline:30905482 doi:10.1016/j.amepre.2018.12.013

9 Pettifor A, Lippman SA, Gottert A, Suchindran CM, Selin A, Peacock D, et al. Community mobilization to modify harmful gender norms and reduce HIV risk: results from a community cluster randomized trial in South Africa. J Int AIDS Soc. 2018;21:e25134. Medline:29972287 doi:10.1002/jia2.25134

10 Hargreaves J, Hatcher A, Strange V, Phetla G, Busza J, Kim J, et al. Process evaluation of the Intervention with Microfinance for AIDS and Gender Equity (IMAGE) in rural South Africa. Health Educ Res. 2010;25:27-40. Medline:19797337 doi:10.1093/her/cyp054

11 Abramsky T, Devries K, Kiss L, Francisco L, Nakuti J, Musuya T, et al. A community mobilisation intervention to prevent violence against women and reduce HIV/AIDS risk in Kampala, Uganda (the SASA! Study): study protocol for a cluster randomised controlled trial. Trials. 2012;13:96. Medline:22747846 doi:10.1186/1745-6215-13-96

12 Heise L. What works to prevent partner violence? An evidence overview. 2011.

13 Stern E, Nyiratunga R. A Process Review of the Indashyikirwa Couples Curriculum to Prevent Intimate Partner Violence and Support Healthy, Equitable Relationships in Rwanda. Soc Sci. 2017;6:63. doi:10.3390/socsci6020063

14 Stern E, Carlson K. Indashyikirwa Women's Safe Spaces: Informal Response for Survivors of IPV within a Rwandan Prevention Programme. Soc Sci. 2019;8:76. doi:10.3390/socsci8030076

15 Dunkle K, Heise L, Stern E, McLean L. Indashyikirwa IPV Prevention Trial in Rwanda (ClinicalTrials.gov Identifier: NCT03477877). 2018.

16 Dunkle K, Stern E, Chatterji S, Heise L. Indashyikirwa programme to reduce intimate partner violence in Rwanda: Report of findings from a cluster randomized control trial. South Africa: SAMRC, 2019 2019. Report No.

17 (NISR) NISR. Demographic and Health Survey 2014-2015. Kigali, Rwanda: Ministry of Finance and Economic Planning, 2016.

18 Raising Voices. Fidelity to the SASA! Activist Kit. 2017.

19 Hayes RJ, Bennett S. Simple sample size calculation for cluster-randomized trials. Int J Epidemiol. 1999;28:319-26. Medline:10342698 doi:10.1093/ije/28.2.319 
20 Organization WH. Putting women first: Ethical and safety recommendations for research on domestic violence against women. Geneva: World Health Organization, 2001.

21 Singer JD, Willett JB. Applied longitudinal data analysis: Modeling change and event occurrence. New York, NY, US: Oxford University Press; 2003.

22 Moore GF, Audrey S, Barker M, Bond L, Bonell C, Hardeman W, et al. Process evaluation of complex interventions: Medical Research Council guidance. BMJ. 2015;350:h1258. Medline:25791983 doi:10.1136/bmj.h1258

23 Stern E, Martins S, Stefanik L, Uwimpuhwe S, Yaker R. Lessons learned from implementing Indashyikirwa in Rwanda- an adaptation of the SASA! approach to prevent and respond to intimate partner violence. Eval Program Plann. 2018;71:5867. Medline:30125773 doi:10.1016/j.evalprogplan.2018.08.005

24 Barrera M Jr, Castro FG. A heuristic framework for the cultural adaptation of interventions. Clin Psychol Sci Pract. 2006;13:311-6. doi:10.1111/j.1468-2850.2006.00043.x

25 Bernal G, Jiménez-Chafey MI, Domenech Rodríguez MM. Cultural adaptation of treatments: A resource for considering culture in evidence-based practice. Prof Psychol Res Pr. 2009;40:361. doi:10.1037/a0016401

26 Stern E, Heise L. Sexual coercion, consent and negotiation: processes of change amongst couples participating in the Indashyikirwa programme in Rwanda. Cult Health Sex. 2019;21:867-82. Medline:30547723 doi:10.1080/13691058. 2018.1521991

27 Macalino GE, Celentano DD, Latkin C, Strathdee SA, Vlahov D. Risk behaviors by audio computer-assisted self-interviews among HIV-seropositive and HIV-seronegative injection drug users. AIDS Educ Prev. 2002;14:367-78. Medline:12413183 doi:10.1521/aeap. 14.6.367.24075

28 Fenton KA, Johnson AM, McManus S, Erens B. Measuring sexual behaviour: methodological challenges in survey research. Sex Transm Infect. 2001;77:84-92. Medline:11287683 doi:10.1136/sti.77.2.84 